\title{
INTERACTION BETWEEN INTRA-ABDOMINAL PRESSURE AND POSITIVE-END EXPIRATORY PRESSURE
}

\author{
Jamili Anbar Torquato, ,II Jeanette Janaina Jaber Lucato, I,II Telma Antunes, ${ }^{\text {II }}$ \\ Carmen Valente Barbas II
}

doi: $10.1590 / \mathrm{S1807-59322009000200007}$

Torquato JA, Lucato J, Antunes T, Barbas CV. Interaction between intra-abdominal pressure and positive-end expiratory pressure. Clinics. 2009;64:105-12.

OBJECTIVE: The aim of this study was to quantify the interaction between increased intra-abdominal pressure and Positive-End Expiratory Pressure.

METHODS: In 30 mechanically ventilated ICU patients with a fixed tidal volume, respiratory system plateau and abdominal pressure were measured at a Positive-End Expiratory Pressure level of zero and $10 \mathrm{~cm} \mathrm{H}_{2} \mathrm{O}$. The measurements were repeated after placing a $5 \mathrm{~kg}$ weight on the patients' belly.

RESULTS: After the addition of $5 \mathrm{~kg}$ to the patients' belly at zero Positive-End Expiratory Pressure, both intra-abdominal pressure $(p<0.001)$ and plateau pressures $(p=0.005)$ increased significantly. Increasing the Positive-End Expiratory Pressure levels from zero to $10 \mathrm{~cm} \mathrm{H}_{2} \mathrm{O}$ without weight on the belly did not result in any increase in intra-abdominal pressure $(\mathrm{p}=0.165)$. However, plateau pressures increased significantly $(p<0.001)$. Increasing Positive-End Expiratory Pressure from zero to $10 \mathrm{~cm}_{2} \mathrm{O}$ and adding 5 $\mathrm{kg}$ to the belly increased intra-abdominal pressure from 8.7 to $16.8(p<0.001)$ and plateau pressure from 18.26 to $27.2(p<0.001)$. Maintaining Positive-End Expiratory Pressure at $10 \mathrm{cmH}_{2} \mathrm{O}$ and placing $5 \mathrm{~kg}$ on the belly increased intra-abdominal pressure from $12.3+/-1.7$ to $16.8+/-1.7(p<0.001)$ but did not increase plateau pressure $(26.6+/-1.2$ to $27.2+/-1.1-p=0.83)$.

CONCLUSIONS: The addition of a $5 \mathrm{~kg}$ weight onto the abdomen significantly increased both IAP and the airway plateau pressure, confirming that intra-abdominal hypertension elevates the plateau pressure. However, plateau pressure alone cannot be considered a good indicator for the detection of elevated intra-abdominal pressure in patients under mechanical ventilation using PEEP. In these patients, the intra-abdominal pressure must also be measured.

KEYWORDS: Respiratory Mechanics; End-Positive Airway Pressure; Plateau pressures; Intra-abdominal pressure; Positive Pressure Mechanical Ventilation.

\section{INTRODUCTION}

Respiratory system impairment caused by an increase in the intra-abdominal pressure $>15 \mathrm{mmHg}$ has been explored by multiple authors. It has become necessary to assess the behavior of the respiratory system in the presence of mild or even moderate degrees of intra-abdominal hypertension and

\footnotetext{
${ }^{\text {I }}$ Departamento de Patologia, Faculdade de Medicina e Instituto Central do Hospital das Clinicas, São Paulo, Brasil e Universidade Cruzeiro do Sul, São Paulo/SP, Brasil.

II Disciplina de Pneumologia, Faculdade de Medicina e Instituto Central do Hospital das Clinicas, São Paulo/SP, Brasil.

Email: jamilianbar@yahoo.com

Tel.: 5511 3086-2958

Received for publication on August 05, 2008

Accepted for publication on October 17, 2008
}

its interaction with positive-end expiratory pressure (PEEP). It has been observed that mechanical ventilation in patients with elevated abdominal pressure is impaired by increased airway pressure, with important alterations in respiratory mechanics and gas exchange. ${ }^{1,2}$ Hence, many respiratory system measurement results, which were previously attributed to pulmonary conditions alone, may also be the result of alterations in the mechanics of the thoracic cage of which intra-abdominal pressure alterations are the most important. Measurements of the mechanics of the respiratory system must be interpreted in the context of airway pulmonary parenchyma and thoracic cage mechanics. When adjusting the mechanical ventilator, especially for those with an increased respiratory system plateau pressure, the intraabdominal conditions must be monitored in addition to the 
pulmonary parenchyma conditions. The clinical goal must be to identify conditions that could lead to an increase in intra-abdominal pressure and must be corrected to improve the patient's prognosis.

The lung, thoracic cage, and the abdominal cavity comprise a closed system with the diaphragm as the connecting interface. When there is an increase in the abdominal and diaphragmatic pressure, the pleural pressure may be altered and a decrease in total lung capacity, pulmonary compliance, and pulmonary volume may follow.

The adjustments in the PEEP applied to the airways can also be transmitted to the abdomen, contributing to an increase in intra-abdominal pressure. ${ }^{3-5}$

A diagnosis of increased intra-abdominal pressure is rarely made in Intensive Care Units, which leads to poorer prognosis for these patients due to the lack of appropriate and timely interventions. ${ }^{1}$ To date, there is no consensus on the actual value that distinguishes normal and pathological pressure. It is known that the effects of increased abdominal pressure have implications on other organs systems, such as the cardiovascular system, ${ }^{6-8}$ the central nervous system, ${ }^{9}$ liver and visceral systems, ${ }^{10}$ and the renal system. ${ }^{11}$ In cases where the intra-abdominal pressure is increased above normal values, the term "intra-abdominal hypertension" (IAH) is used..$^{3,12-14}$

Clinical examination of the abdomen or abdominal perimeter is not appropriate for calculating IAP. ${ }^{15}$ Measurement of intra-abdominal pressure through the measurement of intravesical pressure is considered to be the gold standard for the measurement of intra-abdominal pressure. ${ }^{16-19}$

Accurately measuring intra-abdominal pressure is extremely important in critically ill patients and in those under mechanical ventilation. Measurement values can alter patients' prognoses by increasing mortality rates. ${ }^{12,16,20}$ Readings of above $20-25 \mathrm{mmHg}$ may indicate the need for surgical abdominal decompression. ${ }^{21}$ Hence, we hypothesized that placing an external weight on the abdomen of critically ill patients would increase the intra-abdominal and airway plateau pressures and that these alterations in the PEEP, in addition to altering the increase in the airway plateau pressure, would also impact the increase in intra-abdominal pressure. We performed a study to quantify these alterations. Our aims were as follows:

* 1 - To observe the effects of placing a $5 \mathrm{~kg}$ weight on the abdomen on intra-abdominal and airway pressures

* 2 - To observe the effects of PEEP variation from 0 to 10 $\mathrm{cm} \mathrm{H}_{2} \mathrm{O}$ on airway pressure and intra-abdominal pressure in mechanically ventilated patients admitted to an intensive care unit (ICU).

\section{MATERIAL AND METHODS}

Thirty patients, who have been admitted to the Intensive Care Unit of the Intensive Care Unit of the Disciplines of Trauma Surgery and Medical Clinics of the Emergency Department of Instituto Central of Hospital das Clínicas ICHC, were sedated and placed under mechanical ventilation and long-term vesical catheterization instituted during routine care of the patient at our facility. Family members and/or tutors agreed to the study protocol by signing a written Informed Consent Form, which was approved by the Ethics Committee for Research Project Analysis - CAPPesq of the Clinical Board of Hospital of Clínicas and School of Medicine of the University of São Paulo, protocol \#668.

The inclusion criteria were: patients who were sedated, exhibited stable hemodynamic mean arterial pressure (MAP) $>65 \mathrm{mmHg}$, were under invasive mechanical ventilation, had been catheterized in the urinary bladder during routine care at the hospital, were aged 18 or older, and had a family member or guardian who had signed an informed consent form.

In our study, we considered the following classifications for intra-abdominal pressure (IAP):

Zero grade: IAP: 0-7 mmHg $\left(0-9 \mathrm{~cm} \mathrm{H}_{2} \mathrm{O}\right)$;

Grade I: IAP: $8-11 \mathrm{mmHg}\left(11-15 \mathrm{~cm} \mathrm{H}_{2} \mathrm{O}\right)$, is an ambiguous condition where there is the possibility of developing intraabdominal hypertension (IAH);

Grade II: IAP: $12-15$ mmHg (16.3-20.4 cm H IAH;

Grade III: IAP: $16-20 \mathrm{mmHg}\left(22-27 \mathrm{~cm} \mathrm{H}_{2} \mathrm{O}\right)$ : severe IAH; Grade IV: IAP: $21-25 \mathrm{mmHg}\left(28.5-34 \mathrm{~cm} \mathrm{H}_{2} \mathrm{O}\right)$ : moderate abdominal compartment syndrome (ACS);

Grade V: IAP > $25 \mathrm{mmHg}\left(34 \mathrm{~cm} \mathrm{H}_{2} \mathrm{O}\right)$ : severe abdominal compartment syndrome (ACS). ${ }^{3,12-14}$

We excluded patients with hemodynamic instability, elevated intra-cranial pressure, pulmonary diseases such as acute respiratory distress syndrome (ARDS), which causes alveolar instability and requires special attention, PEEP higher than $10 \mathrm{~cm} \mathrm{H}_{2} \mathrm{O}$, unstable thorax, drained or non-drained pneumothorax, congestive cardiac failure, or disease that did not allow for the variation of PEEP from 0 to $10 \mathrm{~cm} \mathrm{H_{2 }}$ O. Additionally, we excluded patients who had undergone abdominal or thoracic surgeries, had unresolved abdominal or thoracic trauma, those who presented a "Bogotá bag" abdomen or who had other abdominal pain that contraindicated the placement of weight on the abdomen.

After this selection, the parameters of each patient's ventilator were recorded and vital signs were observed through ICU monitors, pulse oximeters, cardiac monitors, and noninvasive arterial pressure measurements. All patients 
were ventilated with a constant current volume according to the standard protocol used at our facility for the measurement of respiratory plateau pressure and intra-abdominal pressure in $\mathrm{cm}_{2} \mathrm{O}$. As soon as the measurements were recorded, the initial parameters of the ventilator were restored. In order to measure intra-abdominal pressure we used the original method proposed by Kron ${ }^{22}$ as our reference. We used $\mathrm{cm}$ $\mathrm{H}_{2} \mathrm{O}$ as our preferred unit $\left(1 \mathrm{mmHg}=1.36 \mathrm{~cm} \mathrm{H}_{2} \mathrm{O}\right)$. We also measured the plateau pressure with PEEP $=0 \mathrm{~cm} \mathrm{H}_{2} \mathrm{O}$ and again with $\mathrm{PEEP}=10 \mathrm{~cm} \mathrm{H}_{2} \mathrm{O}$ with no weight on the abdomen after a stabilization period of 5 minutes. Our measurements of intra-abdominal pressure and respiratory system plateau were then repeated with a $5 \mathrm{~kg}$ weight placed on the patient's abdomen. The intra-abdominal and plateau pressures were measured across all four phases of the protocol (Figure 1).
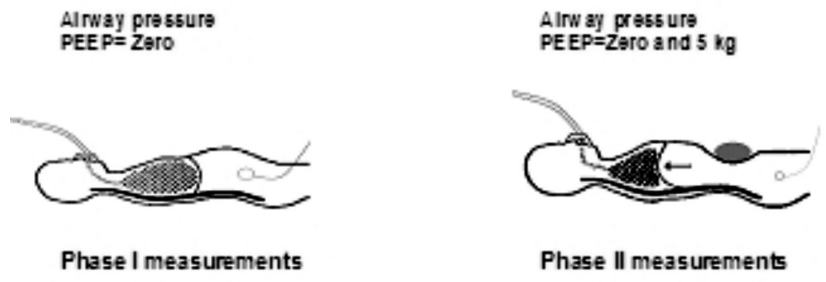

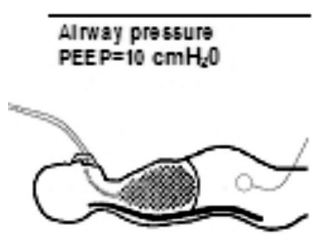

Phase III measurements

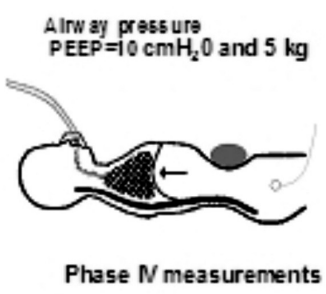

Figure 1 - Different phases of the protocol (I, II, III, IV)

To obtain the respiratory system plateau pressure, the parameters of the mechanical ventilator were adjusted to match a tidal volume of $10 \mathrm{~mL} / \mathrm{kg}$ (ideal body weight), a 2 -sec pause, respiratory rate of $10 \mathrm{rpm}$, flow of $60 \mathrm{~L} / \mathrm{min}$, square wave, and a $\mathrm{FiO}_{2}$ value sufficient to maintain $\mathrm{SatO}_{2}>$ $90 \%$. The patient's weight was obtained from the ideal weight calculated using the formula $50+0.91 \times$ (height -152.4 ) for men and $45.05+0.91 \times$ (height -152.4 ) for women. Plateau pressure was obtained with a PEEP of zero and a PEEP of 10 $\mathrm{cm} \mathrm{H}_{2} \mathrm{O}$, with and without the $5 \mathrm{~kg}$ weight on the abdomen, consistent with the four phases of the protocol.

Deriving the intra-abdominal pressure by measuring the intra-vesical pressure is an indirect approach. The measurement uses a sterile deactivated system at the patient's bedside - measurements are taken using the water column technique ${ }^{19}$ and a vesical catheter. We used the original method developed by Kron, with the patient in the dorsal decubitus position. We set the system equal to zero on the pubic symphysis. We used central venous pressure (CVP) equipment connected to a $1,000 \mathrm{~mL} 0.9 \%$ saline solution bag, two taps, and a $60 \mathrm{~mL}$ Luer-Lok syringe. An 18-gauge needle was placed at the distal end of the equipment. The needle was inserted into the end of a Fowley catheter during culture collection and was promptly removed after the measurement. The Fowley catheter was clamped at its distal end for liquid outflow into the diuresis collector. The system was then filled with saline solution and was set to zero at the level of the pubic symphysis with a ruler that was used to measure central venous pressure. The taps were turned off for the patient and water column. $50 \mathrm{~mL}$ of saline solution was subsequently aspirated from the $1,000 \mathrm{~mL}$ bag. The first tap was turned on and $50 \mathrm{~mL}$ of the saline solution was infused into the patient's bladder through the vesical catheter. The taps were turned off both at the syringe and for the saline solution bag.

After that, the system was balanced, taking the value from the patient's pubic symphysis in the dorsal decubitus position as the zero pressure point. The third end of the central venous pressure equipment, which was parallel to the number scale, was activated to match the intra-abdominal pressure to the atmospheric pressure. The water column reached an equilibrium at a level that translated to a value in the number scale. This was considered the intra-abdominal pressure. The IAP was measured during the patient's expiratory phase under mechanical ventilation. At the end of the protocol, the clamp used to temporarily close the vesical catheter was removed to allow for bladder drainage and the volume of saline solution utilized was subtracted from the patient's urinary output at that time..$^{22}$

After registering the initial and actual values of each patient consistent with the protocol, these measurements were repeated at different PEEP pressures $(0$ and $10 \mathrm{~cm}$ $\mathrm{H}_{2} \mathrm{O}$ ) and abdominal weights ( 0 and $5 \mathrm{~kg}$ ). Before each measurement, a 5-minute interval was allowed for the patient to stabilize and acclimate to the new condition. Measurements for each phase took no more than 7 minutes.

The weight consisted of a $5 \mathrm{~kg}$ bag with a surface that measured $35 \times 27 \mathrm{~cm}$ (an area of $945 \mathrm{~cm}^{2}$ ) with the objective of maintaining a consistent area of abdominal compression and elevating the intra-abdominal pressure (Figure 2).

After data collection, the individuals were readapted to the initial ventilation parameters and hemodynamic conditions, and their other vital signs were checked. The nurse in charge of the patient was advised to subtract the $50 \mathrm{~mL}$ volume of infused saline solution from the patient's urinary output. In case of any instability during data collection, the procedure 

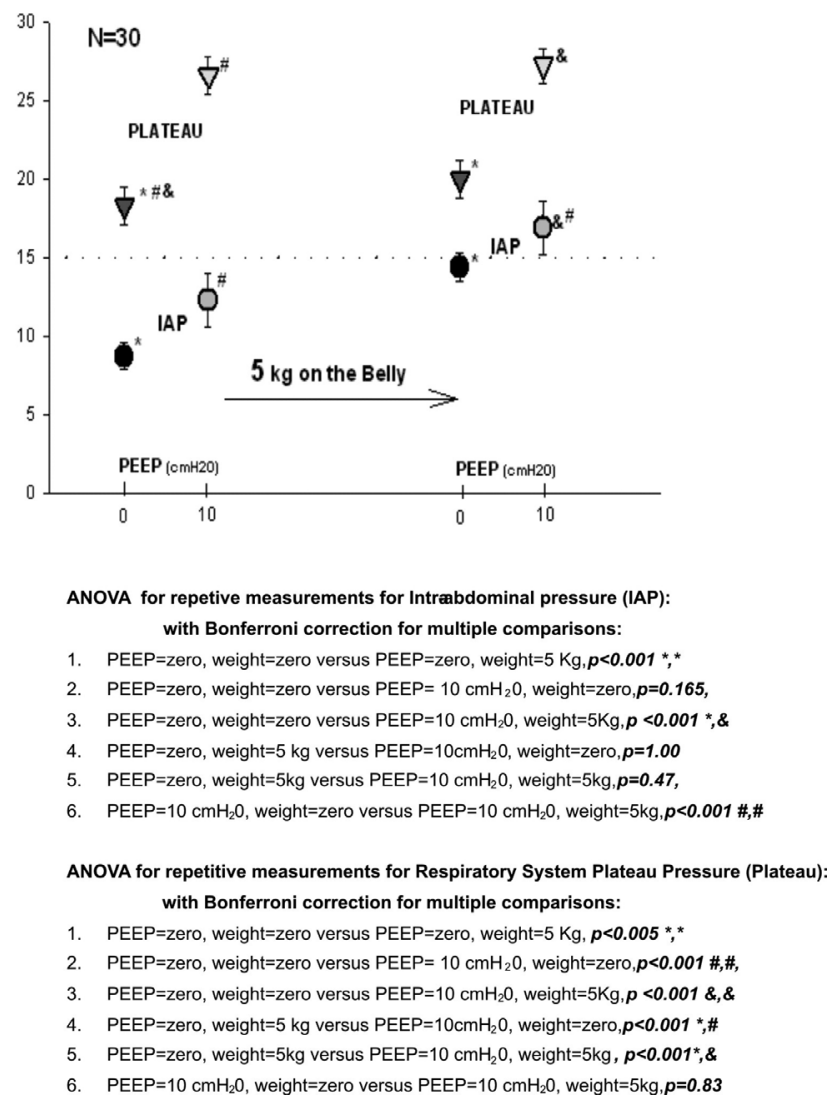

Figure 2 - Changes in intra-abdominal and respiratory system plateau pressure with PEEP and external abdominal weight

was interrupted and the patient was excluded from the protocol. However, such an instability did not occur for any of the patients. The results presented in this study are expressed in terms of means and standard deviations.

To compare the four protocol phases, ANOVA (analysis of variance) was utilized for repeated measurements and Bonferroni's correction was used for multiple comparisons (Software: SPSS, version 11). Statistical significance was set to $p<0.05$.

\section{RESULTS}

Thirty patients ( 26 males, 4 females) were enrolled in the study. Patients had a mean age of $47.30 \pm 23.46$ (18-92) years, mean height of $1.73 \pm 0.1 \mathrm{~m}$, and exhibited comorbidities including pulmonary contusion $(n=4)$, blunt abdominal trauma $(n=4)$, chronic obstructive pulmonary disease (COPD) $(n=3)$, cranial-encephalic trauma $(n=3)$, firearm wound $(n=2)$, septic shock $(n=2)$, bronchopneumonia $(\mathrm{n}=1)$, aspiration pneumonia $(\mathrm{n}=1)$, cholecystectomy $(\mathrm{n}=1)$, thoracoplasty $(n=1)$, gastrectomy $(n=1)$, splenectomy $(n=1)$, stroke $(n=1)$, esophagectomy $(n=1)$, high digestive hemorrhage $(\mathrm{n}=1)$, and appendicectomy $(\mathrm{n}=1)$.

Phase I of the protocol: Measurements of the abdominal and airway pressures showed that the patients presented normal mean IAP values of $8.70 \pm 4.48 \mathrm{~cm} \mathrm{H}_{2} \mathrm{O}$ and that $10 \%$ of the patients met the criteria for intra-abdominal hypertension. None of the patients exhibited a respiratory plateau pressure of above $35 \mathrm{~cm} \mathrm{H}_{2} \mathrm{O}$. The mean Plateau pressure was $18.27 \pm 6.12 \mathrm{~cm} \mathrm{H}_{2} \mathrm{O}$ (Tables 1 and 2).

When the Phase II measurements were performed after placing the $5 \mathrm{~kg}$ weight on the patients' abdomen and maintaining the airways at zero PEEP, the intra-abdominal pressure in all patients increased significantly from $8.70 \pm 4.48$ to $14.33 \pm 4.82(p<0.001)$, reaching mild intraabdominal hypertension. This IAP elevation influenced the plateau pressure, which increased significantly from $18.27 \pm 6.12$ to $20.00 \pm 6.57(p=0.005)$.

In phase III, during which PEEP was elevated from 0 to $10 \mathrm{cmH}_{2} \mathrm{O}$ without the abdominal weight, the intra-abdominal pressure did not show a statistically significant increase, going from $8.70 \pm 4.48$ to $12.30 \pm 9.62$ $\mathrm{cmH}_{2} \mathrm{O}(p=0.165)$, whereas the plateau pressure increased significantly, from $18.30 \pm 6.12 \mathrm{cmH}_{2} \mathrm{O}$ to $26.60 \pm 6.45$ $\mathrm{cmH}_{2} \mathrm{O}(p<0.001)$.

In phase IV, the PEEP was raised from 0 to $10 \mathrm{cmH}_{2} \mathrm{O}$ and a $5 \mathrm{~kg}$ weight was placed on the patients' abdomen, resulting in a significant increase in intra-abdominal pressure, from $8.70 \pm 4.48$ to $16.83 \pm 9.51 \mathrm{cmH}_{2} \mathrm{O}(p<0.001)$, as well as significantly increased plateau pressure, from $18.27 \pm 6.12 \mathrm{cmH}_{2} \mathrm{O}$ to $27.20 \pm 6.04 \mathrm{cmH}_{2} \mathrm{O}(p<0.001)$.

When shifting from Phase II to Phase III by increasing PEEP from 0 to $10 \mathrm{cmH}_{2} \mathrm{O}$ and removing the abdominal weight, the decrease in the intra-abdominal pressure

Table 1 - Intra-abdominal and plateau pressures for each phase of the protocol

\begin{tabular}{lcccccccc}
\hline & \multicolumn{3}{c}{ INTRA-ABDOMINAL PRESSURE $\left(\mathrm{cmH}_{2} \mathrm{O}\right)$} & \multicolumn{5}{c}{ PLATEAU PRESSURE $\left(\mathrm{cmH}_{2} \mathrm{O}\right)$} \\
\hline PEEP & 0 & 0 & 10 & 10 & 0 & 0 & 10 & 10 \\
WEIGHT & 0 & 5 & 0 & 5 & 0 & 5 & 0 & 5 \\
PHASE & $\mathrm{I}$ & $\mathrm{II}$ & $\mathrm{III}$ & $\mathrm{IV}$ & $\mathrm{I}$ & $\mathrm{II}$ & $\mathrm{III}$ & $\mathrm{IV}$ \\
MEAN & 8.70 & 14.33 & 12.25 & 16.83 & 18.27 & 20.00 & 26.57 & 27.20 \\
SD & 4.48 & 4.90 & 9.62 & 9.51 & 6.12 & 6.57 & 6.45 & 6.04 \\
\hline
\end{tabular}


Table 2 - Intra-abdominal pressure grade at the beginning of the protocol

\begin{tabular}{ccc}
\hline IAP $\left(\mathrm{cmH}_{2} \mathrm{O}\right)$ & IAP grade & Total $(\mathrm{n}=30)$ \\
\hline $0-10$ & Normal & $21(70 \%)$ \\
$10.5-15$ & Intermediary & $6(20 \%)$ \\
$15.5-21$ & IAH & $3(10 \%)$ \\
\hline
\end{tabular}

IAP: intra-abdominal pressure, IAH: intra-abdominal hypertension.

was not statistically significant (Figure 2), going from $14.33 \pm 4.90$ to $12.25 \pm 9.62(p=1.00)$. However, the plateau pressure increased significantly, from $20.00 \pm 6.57 \mathrm{cmH}_{2} \mathrm{O}$ to $26.57 \pm 6.45 \mathrm{cmH}_{2} \mathrm{O}(p<0.001)$. We kept the $5 \mathrm{~kg}$ weight on the patients' abdomen and increased PEEP from 0 to $10 \mathrm{cmH} 2 \mathrm{O}$ to move from phase II to phase IV. During this time (Figure 2) there was no significant increase in intra-abdominal pressure, from $14.33 \pm 4.90$ to $16.83 \pm 9.51$ $\mathrm{cmH}_{2} \mathrm{O}(p=0.47)$. However, the plateau pressure increased significantly with PEEP going from $20.00 \pm 6.57$ to $27.20 \pm 6.04 \mathrm{cmH}_{2} \mathrm{O}(p<0.001)$.

Finally, when moving from phase III to phase IV by placing a $5 \mathrm{~kg}$ weight on the abdomen of the patients associated with a PEEP of $10 \mathrm{cmH}_{2} \mathrm{O}$ (Figure 2), we observed significantly increased intra-abdominal pressure (moving from $12.30 \pm 9.62$ in the initial phase to $16.83 \pm 9.51$ $\left.\mathrm{cmH}_{2} \mathrm{O}(p<0.001)\right)$. However, the plateau pressure showed a statistically non significant increase, going from $26.60 \pm 6.45$ $\mathrm{cmH}_{2} \mathrm{O}$ to $27.20 \pm 6.04 \mathrm{cmH}_{2} \mathrm{O}(p=0.83)$.

\section{DISCUSSION}

The aim of the present study was to verify the association between the intra-abdominal pressure, which is influenced by many factors, such as for instance hemodialysis, ${ }^{23}$ and the airway plateau pressure in mechanically ventilated ICU patients with different PEEP values and weights on the abdomen to simulate intraabdominal hypertension. We simulated increasing IAP by placing a weight varying from 0 to $5 \mathrm{~kg}$ on the patients' abdomen, which elevated IAP means from the normal Grade to values that reached Grade III.

At the initial conditions, with a volume control of $10 \mathrm{~mL} /$ $\mathrm{kg}$ without PEEP and at a respiratory frequency of $10 \mathrm{rpm}$, we observed that $10 \%$ of the patients ( 3 out of 30 ) presented an IAP> $15.5 \mathrm{~cm} \mathrm{H}_{2} \mathrm{O}$. This value is characteristic of intraabdominal hypertension; none of our patients presented a diagnosis of abdominal compartment syndrome. After the 5 $\mathrm{kg}$ weight had been placed on the abdomens of our patients, we observed a significant increase in intra-abdominal pressure and in the plateau pressure. This was used to simulate situations that can occur in ICU patients, such as gastric or abdominal distension, urinary retention, or the effects of compression bandages. ${ }^{15}$

Along with IAH, it is common to observe an increase in the intra-thoracic and pleural pressure, leading to the formation of atelectasia and edema as well as decreasing the functional residual capacity. Ventilated patients may also present conditions such as auto-PEEP, increasing airway pressure, barotraumas, decreases in respiratory system compliance, hypoxia, hypercarbia, and infection risk, all of which can hinder mechanical ventilation and weaning in such patients. $22-26$

Patients under mechanical ventilation, with a PEEP of $10 \mathrm{~cm} \mathrm{H}_{2} \mathrm{O}$, and with increased IAP following the placement of a 5-kg weight on the abdomen, showed a significant increase in intra-abdominal pressure, although the plateau pressure did not increase significantly. Thus, we suggest that it is advisable to measure the intra-vesical pressure in mechanically ventilated ICU patients. We argue that this would allow for early detection of intra-abdominal hypertension and prophylaxis of its complications, such as intracranial pressure and multiple organ and system dysfunction. ${ }^{16}$ In patients admitted to the ICU, it is important to verify the presence of gastric distension, inadvertent urinary retention, signs and symptoms of mesenteric ischemia, liver and pancreas dysfunction and ascites, as well as to monitor the volume of intra-cavitary infusion in patients undergoing peritoneal dialysis. ${ }^{11,26-29}$ Compression bandaging on the abdomen must be avoided, gastric and vesical emptying are critical, and computer tomography $\mathrm{CT} /$ angio-resonance of the abdomen is needed in cases of suspected intra-abdominal disease. If possible, intra-vesical pressure should be measured during the patient's stay in the ICU. In cases where intra-abdominal pressures exceed 20-25 $\mathrm{mmHg}$, surgical decompression of the abdomen becomes necessary. After surgical decompression, an improvement in the $\mathrm{PaO}_{2} / \mathrm{FIO}_{2}$ ratio as well as in pulmonary volume will often be observed. ${ }^{16}$

The present study showed that when PEEP was augmented from 0 to $10 \mathrm{~cm} \mathrm{H}_{2} \mathrm{O}$ with no weight on the abdomen, patients exhibited a significant increase in airway plateau pressure and a non-significant increase in the intravesical pressure. However, $10 \%$ of our patients ( 3 of 30 ) presented an intra-abdominal pressure of more than $15 \mathrm{~cm}$ $\mathrm{H}_{2} \mathrm{O}$ after PEEP, typical of an intra-abdominal hypertension condition with potential clinical complications.

Thus, every time the respiratory system is pressurized, it is necessary to check the vesical pressure and, if necessary, readjust the mechanical ventilator pressures. When adjusting the mechanical ventilator, one must take into account whether the patient is under controlled or assisted ventilation, as the ventilatory mode directly interferes with 
the intra-thoracic and intra-abdominal pressure levels. The use of assisted ventilation makes the patient contract their diaphragm musculature, thereby decreasing the pleural pressure, whereas controlled ventilation makes the pleural and abdominal pressure go positive. ${ }^{16,29,30}$

In several cases in our study, intra-abdominal hypertension was caused by the $5 \mathrm{~kg}$ weight placed on patients' abdomen. In these instances, when a $10 \mathrm{~cm} \mathrm{H}_{2} \mathrm{O}$ PEEP was added the increase in intra-abdominal pressure was not statistically significant. However, in two of these patients, the IAP was greater than $15 \mathrm{~cm} \mathrm{H}_{2} \mathrm{O}$, suggesting aggravated intra-abdominal pressure. Thus, we recommend that patients in ICUs under mechanical ventilation be monitored to measure IAP and airway pressure whenever the parameters of the mechanical ventilator are adjusted. The goal should be to optimize ventilatory support and to avoid elevated intra-abdominal pressure and potential associated deleterious effects.

Many studies have recently emphasized that the occurrence of intra-abdominal hypertension in the ICU leads to a decrease in blood flow to the intra-abdominal organs, resulting in tissue hypoxia, interstitial edema, and multiple organ failure, and increasing the morbidity and mortality of critically ill patients. ${ }^{23,25,31,32}$ The renal system also suffers with the elevation of the intra-abdominal pressure due to decreased renal blood flow, glomerular filtration, and urinary output, which may lead to increased renal vascular resistance as a consequence of mechanical compression. ${ }^{27}$ Hemodialysis can significantly reduce intra-abdominal pressure and may also cause a loss of blood volume. ${ }^{29,33}$

Hence, we recommend that all mechanically ventilated patients should have their hourly diuresis rates carefully monitored. We recommend regular assessment of renal function. In case of oliguria that is non-responsive to volemic replacement, the possibility of the presence of intra-abdominal hypertension must be taken into account and intra-vesical pressure must be monitored. In positive cases, the possible cause of intra-vesical pressure increments must be investigated and an immediate attempt must be made to decrease the airway pressure, if possible, as a means of improving the renal response.

The respiratory dysfunctions that result from increased intra-abdominal pressure may include the onset of atelectasia, a decrease in functional residual capacity, as well as a respiratory system pressure-volume curve shift and a lowering of the inflexion point. ${ }^{16,26,27,34}$ In the present study, we used volume control ventilation of $10 \mathrm{~mL} / \mathrm{kg}$ in order to verify the alterations in the plateau pressure and intra-vesical pressure without the influence of possible variations in pulmonary and thoracic cage compliance due to variations in the instantaneous volume. Thus, situations that alter pulmonary and/or thoracic cage elasticity will interfere with the measurement of airway plateau pressure.

The monitoring of mechanically ventilated ICU patients must include intermittent or continuous measurement of intra-abdominal pressure. The goal should be to maintain intra-abdominal pressures that are safe for patients, thereby preventing the occurrence of multiple organ dysfunction due to a non-detected increase in intra-abdominal pressure. ${ }^{16}$

The concomitant monitoring of airway plateau pressure and intra-abdominal pressure guarantees that the hemodynamic and ventilatory supports will be optimized. This in turn may lead to a decrease in morbidity/mortality for this population of critically-ill patients. . $6,27,31,32,35,36$

\section{CONCLUSIONS}

The placement of a $5 \mathrm{~kg}$ weight on the abdomen significantly increased the intra-abdominal pressure and the airway plateau pressure, confirming that intra-abdominal hypertension elevates the plateau pressure. A PEEP of $10 \mathrm{~cm}$ $\mathrm{H}_{2} \mathrm{O}$ did not significantly increase the intra-abdominal pressure when its values were $<15 \mathrm{~cm} \mathrm{H}_{2} \mathrm{O}$. The placement of a $5 \mathrm{~kg}$ weight on the abdomen concomitant with a PEEP of $10 \mathrm{cmH}_{2} \mathrm{O}$ under mechanical ventilation increased the risk of intra-abdominal hypertension in only $36.6 \%$ of the patients. When a $5 \mathrm{~kg}$ weight was placed on the abdomen of patients under mechanical ventilation with a PEEP of $10 \mathrm{~cm}$ $\mathrm{H}_{2} \mathrm{O}$, there was a significant increase in the intra-abdominal pressure but no corresponding increase in airway plateau pressure. Consequently, we suggest that the plateau pressure alone cannot be considered a good indicator for the detection of elevated intra-abdominal pressure in patients under mechanical ventilation using PEEP. In these patients, we must measure the intra-abdominal pressure as well.

\section{ACKNOWLEDGMENTS}

The authors thank Prof. Dário Birolini, Prof. Carlos Ribeiro de Carvalho, Prof. Dr. Renato Sergio Poggetti, Dr. Edson Pedro Rocha and Dr. Luiz Monteiro for their collaboration during the protocol and all the residents and physical therapists working in our units for providing special care to the patients during the protocol. 


\section{REFERENCES}

1. Ranieri VM, Brienza N, Santostasi S, Puntillo F, Mascia L, Vitale N, et al. Impairment of lung and chest wall mechanics in patients with acute respiratory distress syndrome. Am J Resp Crit Care Med.1997;56:108291.

2. Amato MB, Barbas CS, Medeiros DM, Magaldi RB, Schettino GP, Lorenzi-Filho $\mathrm{G}$, et al. Effect of a protective ventilation strategy on mortality in the acute respiratory distress syndrome. N Engl J Med. 1998;338:347-54.

3. Malbrain M. Intra-abdominal pressure in intensive care unit: clinical tool or toy. Yearbook of Intensive Care an Emergency Medicine. SpringerVergag, Berlin. 2001;547-85.

4. Loring SH, Mead J. Action of diaphragm on the rib cage inferred from a force - balance analyses. J.Appl. Physiol. 1982;53:756-60.

5. Simon RJ, Friedlander MH, Ivatury RR, DiRaimo R, Machiedo GW. Hemorrhage lowers the threshold for intra-abdominal hypertension induced pulmonary dysfunction. J.Trauma. 1997;42:398-405.

6. Richardson JD, Trinkee JK. Hemodynamic and respiratory alterations with increased intra-abdominal pressure. J Surg. 1976;20:401-4.

7. Ridings PC, Bloomfield GL, Blocher GR, Sugerman HJ. Cardiopulmonary effects of raised intra-abdominal pressure before and after intravascular volume expansion. J Trauma. 1995; 39:1071-5.

8. Cullen DJ, Coyle JP, Teplick R, Long MC. Cardiovascular, pulmonary, and renal effects of massively increased intra-abdominal pressure in critically ill patients. Crit Care Med. 1989; 17:118-21.

9. Bloomfield GL, Ridings PC, Blocher CR, Marmaru A, Sugerman HJ. A proposed relationship between increased intra-abdominal, intrathoracic, and intracranial pressure. Crit Care Med. 1997;25:496-503.

10. Diebel LN, Dulchavsky SA, Brown WJ. Splanchnic ischemia and bacterial translocation in the abdominal compartment syndrome. $\mathrm{J}$ Trauma. 1997;43:852-5.

11. Bradley SE, Bradley GP. The effect of increased intra-abdominal pressure on renal function in man. J Clin Invest. 1947;26:1010-22.

12. Malbrain ML. Abdominal perfusion pressure as a prognostic marker in intra-abdominal hypertension. In: Vincent J L (ed). Year Book of Intensive Care and Emergency Medicine. Berlin: Springer. 2002;792-814.

13. Malbrain ML. Is it wise not to think about intra-abdominal hypertension in the ICU? Curr Opin Crit Care. 2004;10:132-45.

14. Cheatham ML, White MW, Sagraves SG, Johnson JL, Block EF. Abdominal Perfusion pressure: a superior parameter in the assessment of intra-abdominal hypertension. J. Trauma-Injury Infection \& Critical Care. 2000;49:621-7.

15. Van Mieghem N, Verbrugghe W, Daelemans R, Lins R and Malbrain MLNG. Can abdominal perimeter be used as an accurate estimation of intra-abdominal pressure? Crit Care. 2003;7(Suppl 2):P183.

16. Malbrain ML, Deeren D, De Potter TJ. Intra-abdominal hypertension in critically ill: it is time to pay attention. Curr Opin Crit Care. 2005;11:15671.

17. Fusco MA, Martin RS, Chang MC. Shayn. Estimation of intra-abdominal pressure by bladder pressure measurement: validity and methodology. J.Trauma. 2001;50:297-302.
18. Lee SL, Anderson JT, Kraut EJ, Wisner DH, Wolfe BM. A simplified approach to the diagnosis of elevated intra-abdominal pressure. J.Trauma. 2002;52:1169-72.

19. Malbrain ML. Different Techniques to measure intra-abdominal pressure (IAP): time for a critical re-appraisal. Int Care Med. 2004;30:357-71.

20. Sugerman HJ, Bloomfield GL, Saggi BW. Multisystem organ failure secondary to increased intra-abdominal pressure. Infection. 1999;27:616.

21. Sanchez NC, Tenofsky PL, Dort JM, Shen LY, Helmer SD, Smith RS What is normal intra-abdominal pressure? Am Surg . 2001;67:243-8.

22. Kron IL, Herman PK, Nolan SP. The measurement of intra-abdominal pressure as a criterion for abdominal re-exploration. Ann Surg. 1984;199:28-30.

23. Bonfim RF, Goulart AG, Torquato JA. Effect of hemodialysis on intraabdominal pressure. Clinics. 2007;62:145-50.

24. Pelosi P, Cereda M, Foti G, Giacomini M, Pesenti A. Alterations of lung and chest wall mechanics in patients with acute lung injury: effects of positive end-expiratory pressure. Am J Respir Crit Care Med. 1995;152:531-7.

25. Sugerman HJ, Bloomfield GL, Saggi BW. Multisystem organ failure secondary to increased intraabdominal pressure. Infection. 1999;27:616.

26. Barbas CS, de Matos GF, Pincelli MP, da Rosa Borges E, Antunes T, de Barros JM, et al. Mechanical ventilation in acute respiratory failure: recruitment and high positive end expiratory pressure are necessary. Curr Opin Crit Care. 2005;11:18-28.

27. Harman PK, Kron IL, McLachlan HD, Freedlender AE, Nolan SP Elevated intra-abdominal pressure and renal function. Ann Surg. 1982;196:594-7.

28. Bonfim RF, Goulart AG, FU C, Torquato JA. Effect of hemodialysis on intra-abdominal pressure. Clinics. 2007;62:145-50.

29. Malbrain ML, Chiumello D, Pelosi P, Wilmer A, Brienza N, Malcangi V. Prevalence of intra-abdominal hypertension in critically patients: a multicenter epidemiological study. Intensive Care Med. 2004;30:8229.

30. Gattinoni L, Chiumello D, Carlesso E, Valenza F. Bench-to-bedside review: chest wall elastance in acute lung injury/acute respiratory distress syndrome patients. Crit Care. 2004; 8:350-5.

31. Mutoh T, Lamm WJ, Embree LJ, Hildebrandt J, Albert RK. Abdominal distension alters regional pleural pressures and chest wall mechanics in pigs in vivo. J Appl Physiology.1991;70:2611-8.

32. Malbrain ML, Chiumello D, Pelosi P, Bihari D, Innes R, Ranieri VM, et al. Incidence and prognosis of intra-abdominal hypertension in a mixed population of critically ill patients: a multicenter epidemiological study. Crit Care Med. 2005;33:315-22.

33. Biancofiore G, Bindi ML, Romanelli AM, Bisa M, Boldrini A, Consani $\mathrm{G}$, et al. Postoperative intra-abdominal pressure and renal function after liver transplantation. Arch Surg. 2003;138:703-6. 
34. Pelosi P, Foti G, Cereda M, Vicardi P, Gattinoni L. Effects of carbon dioxide insufflations for laparoscopy cholecystectomy on respiratory system. Anaesthesia. 1996;51:744-9.

35. Malbrain ML, Deeren D, Nieuwendiijk R. Partitioning of respiratory mechanics in intra-abdominal hypertension. Intensive Care Med. 2003;29:S85.
36. Anbar JT, Antunes T, Barbas CSV. Influence of PEEP and external abdominal weight in airway and intra-abdominal pressures in mechanically ventilated ICU patients. Am J Respir Crit Care Med. 2005;A665 